\title{
Ecologically relevant neurobehavioral assessment of the development of threat learning
}

\author{
Julie Boulanger Bertolus, ${ }^{1}$ Anne-Marie Mouly, ${ }^{1}$ and Regina M. Sullivan ${ }^{2}$ \\ ${ }^{1}$ Lyon Neuroscience Research Center, INSERM U1028; CNRS UMR5292; University Lyon1, Lyon, France; ${ }^{2}$ Emotional Brain Institute, \\ Nathan Kline Institute, Child and Adolescent Psychiatry, New York University School of Medicine, New York, New York 10010, USA
}

\begin{abstract}
As altricial infants gradually transition to adults, their proximate environment changes. In three short weeks, pups transition from a small world with the caregiver and siblings to a complex milieu rich in dangers as their environment expands. Such contrasting environments require different learning abilities and lead to distinct responses throughout development. Here, we will review some of the learned fear conditioned responses to threats in rats during their ontogeny, including behavioral and physiological measures that permit the assessment of learning and its supporting neurobiology from infancy through adulthood. In adulthood, odor-shock conditioning produces robust fear learning to the odor that depends upon the amygdala and related circuitry. Paradoxically, this conditioning in young pups fails to support fear learning and supports approach learning to the odor previously paired with shock. This approach learning is mediated by the infant attachment network that does not include the amygdala. During the age range when pups transition from the infant to the adult circuit (10-15 d old), pups have access to both networks: odor-shock conditioning in maternal presence uses the attachment circuit but the adult amygdala-dependent circuit when alone. However, throughout development (as young as $5 \mathrm{~d}$ old) the attachment associated learning can be overridden and amygdala-dependent fear learning supported, if the mother expresses fear in the presence of the pup. This social modulation of the fear permits the expression of defense reactions in life threatening situations informed by the caregiver but prevents the learning of the caregiver itself as a threat.
\end{abstract}

What an animal needs to learn to survive changes based on the phase of development. In altricial species for example, the primary focus of the newborn is to learn about the caregiver in a manner that produces approach and prosocial behaviors, while adults need to learn about food and danger that involve both approach and avoidance behaviors. This specialized infant learning system ensures attachment to the caregiver, including ensuring that the pair maintains contact and the infant receives the nutrition and nurturing required for normal neurobehavioral development. Learning of this attachment begins in utero (Pedersen and Blass 1982; Schaal et al. 1998; Mennella et al. 2001) but continues after birth and is supported by unique features of the neurobehavioral conditioning system (Coureaud et al. 2006; Pattwell et al. 2013; Callaghan et al. 2014; Perry and Sullivan 2014; Rincón-Cortés and Sullivan 2014). Over the course of development, this conditioning system gradually loses its unique infant characteristics and transitions into the adult system. Here we review the development of the attachment system and how it transitions to the threat conditioning system as the infant transitions to independence just a few weeks after birth.

Threat conditioning involves pairing an initially neutral conditional stimulus (CS), such as an odor or tone, with a fearinducing stimulus, called the unconditioned stimulus (US), such as a mild electric shock. After a few CS-US pairings, the animal develops a conditioned threat or fear response to the CS cue (Pavlov 1927; Davis 1989; Fanselow 1994; LeDoux 2000). This Pavlovian learning is widely distributed in the animal kingdom, ranging from worms (Rankin 2004), fish (Overnier and Curnow 1969; Drew et al. 2005), birds (Longo et al. 1962), rodents (Davis 1989), nonhuman primates (Kalin et al. 2004), and humans (Delgado et al. 2006). While fear conditioning has been abundantly used in the rodent literature to investigate the neurobiology of

\section{Corresponding author: regina.sullivan@nyumc.org}

Article is online at http://www.learnmem.org/cgi/doi/10.1101/lm.042218. 116. learning and memory in adults, it also provides a useful template to highlight developmental differences in learning. Since the auditory and visual sensory system show delayed maturation in infant rodents, early life learning studies must rely on the olfactory system that is functional at birth (Alberts 1984).

It is not surprising that infant threat (odor-shock) conditioning and expression differs from adults since many of the brain areas considered critical in adult threat conditioning have delayed functional development during infancy (Crain et al. 1973; Rosselli-Austin and Altman 1979; Bayer 1980; McLean and Shipley 1991; Berdel et al. 1997; Sullivan et al. 2000a; Moriceau et al. 2006; Thompson et al. 2008; Raineki et al. 2010a). Indeed, developmental research has documented that as the brain matures and additional brain areas are incorporated into the learning circuit, the features of adult learning emerge (Stanton 2000; Sullivan et al. 2000a; Kim and Richardson 2010). But in this review, we go beyond this by describing how some of these brain areas show unique neurobehavioral functioning during development to permit age-specific learning and the learning of age relevant behaviors, rather than immature versions of adult learned responses.

\section{Ontogenetic development of defense responses} to natural threats: major transitions in expression at PN10 with amygdala emergence

Predator pressure varies throughout the animal's life and the ability to respond appropriately to each stage-specific threat is important for survival. Therefore, as the threat changes throughout the

(C) 2016 Boulanger Bertolus et al. This article is distributed exclusively by Cold Spring Harbor Laboratory Press for the first 12 months after the full-issue publication date (see http://learnmem.cshlp.org/site/misc/terms.xhtml). After 12 months, it is available under a Creative Commons License (AttributionNonCommercial 4.0 International), as described at http://creativecommons. org/licenses/by-nc/4.0/. 
animal's life, related defense responses also change (Pongrácz and Altbäcker 2000; Wiedenmayer 2009; Putman et al. 2015). Responses to threat in infancy are thus elicited by distinct stimuli and mediated by distinct neural circuits than in adults. While the main topic of this review is not defense responses per se, we briefly review these responses as they are used to study memory mechanisms through ontogeny.

In older pups and adults, threat conditioning produces a cue that has acquired threatening properties that are quite similar to responses to naturally threatening stimuli, especially in early life as the supporting neural networks and motor responses emerge. When an organism is confronted with a threat, it produces innately determined defensive behaviors, which are species-specific (Bolles 1970). In rats, the behavioral repertoire of defense reactions in response to an environmental threat is complex and varies with the animal's age and context of the threat. In adult rats, freezing is one of the most used behavioral measures of fear. It is a well-investigated species-specific defense reaction marked by an absence of all movement except for respiration (Blanchard and Blanchard 1969a; Bolles and Collier 1976). It is a complex behavior composed of many different behaviors, such as crouching, ears back, and piloerection, and has quickly become "the golden standard for assessing fear" (Maren 2008), especially since it allows computer-based scoring and automation of the measure (Anagnostaras et al. 2000). In pups, the onset of freezing behavior has been of interest as a way of understanding the ontogeny of defensive responding. By postnatal day (PN) 23 (weaning age), many of the components of the complex freezing response are present, although how they are combined and the duration of the subcomponents still differ from adults (Bolles and Woods 1964). Importantly pups do have a freezing response by PN10 as assessed by presentation of learned or naturally threatening odors, although the response is not as complex as adults and appears to be primarily defined as immobility with some muscle tension (Takahashi 1994a,b; Moriceau et al. 2004).

As we consider the development of threat behaviors, it should also be noted that the complex behavioral response to threat in adults depends on the level of fear and environmental options for behaviors. Specifically, hiding, freezing, or attacking is determined by whether or not an escape or hiding place is known, but also the proximity of the threat as well as its level and what the animal has learned about that threat. This is discussed in the literature as Predatory Imminence Continuum and suggests that the defensive responses will change as the level of threat changes (Blanchard and Blanchard 1969b, 1989; Bolles and Fanselow 1980). The main assumption of the Predatory Imminence Continuum is that as threat levels change, defensive response strategies change. For example, if a predator or threat is present and the animal is in a confined area without an escape route, adult rats will freeze, while they will escape if given the opportunity or attack if the predator is engaged. This has not been directly assessed in pups, although it appears that young pups and young children typically approach their caregiver when threatened (Rajecki et al. 1978), the option of attack does not emerge until after weaning age (Collier and Bolles 1980) and freezing to the predator odor has not yet developmentally emerged until PN10 (Takahashi 1992; Wiedenmayer and Barr 1998; Moriceau et al. 2004).

In the infant rodent research, because freezing does not emerge until PN10, assessment of threat responding has also relied on approach/avoidance tests to assess the functional emergence of responses to threatening cues, such as a Y-maze or a two-odor choice (Cornwell-Jones and Sobrian 1977; Haroutunian and Campbell 1979; Johanson and Teicher 1980; Kleitman and Satinoff 1982; Sullivan et al. 2000a). For example, newly born pups can approach a maternal odor and will avoid an odor pre- viously paired with malaise induced by high shock or $\mathrm{LiCl}$ (Cornwell-Jones and Sobrian 1977; Rudy and Cheatle 1977; Haroutunian and Campbell 1979; Johanson and Teicher 1980; Kucharski and Spear 1984; Sullivan et al. 1986; Shionoya et al. 2006; Raineki et al. 2009).

Disruption of ongoing behaviors can also be used to measure defense responses, such as exploration, eating, drinking, or grooming. In adults, these behaviors have been shown to be inhibited in the presence of a threatening stimulus (Blanchard and Blanchard 1989; Blanchard et al. 1990). This inhibition of ongoing behavior in response to threat is also seen in pups as they transition to independence around weaning (Bronstein and Hirsch 1976), and includes reduced play (Siviy et al. 2006).

Ultrasonic vocalizations (USV) have also been used to assess the developmental emergence of threat responses. In adults, these vocalizations are emitted around $22 \mathrm{kHz}$ in aversive contexts such as predator encounter (Blanchard et al. 1991; Brudzynski and Ociepa 1992), an agonistic situation (Lore et al. 1976; Van Der Poel and Miczek 1991), or in response to noxious stimuli (Kaltwasser 1990; Van Der Poel and Miczek 1991; Wöhr et al. 2005; Hegoburu et al. 2011). Newborn infant rats emit USVs around $40 \mathrm{kHz}$ in physiologically challenging situations, such as cold distress or noxious stimulus such as shock (Allin and Banks 1971; Blumberg and Alberts 1990; Barr et al. 2015; Boulanger Bertolus et al. 2015). This USV response also occurs to removal of the mother within a temperature controlled environment and is presumably used as a distress call based on the removal of social stimuli and not the presentation of direct threat (Noirot 1968; Hofer and Shair 1978; Gandal et al. 2010; Bader et al. 2011; Shair 2014). Indeed, it is possible that removal of the caregiver might be a threat signal unique to early life, although this needs further exploration. Both adult and infant USVs are decreased by anxiolytic drugs and increased by anxiogenic drugs (Gardner 1985; Insel et al. 1986; Cuomo et al. 1988; Branchi et al. 2001; Jelen et al. 2003), suggesting that they reflect an aversive emotional state of the animal, although the pharmacology supporting infant and adult USV appears to diverge (Simola 2015). Moreover, at least in older pups with a functional amygdala ( $>$ PN10), the presence of an imminent threat, such as predator odor presentation, inhibits USV emission (Takahashi 1992; Shair et al. 1998; Hofer et al. 2001; Wiedenmayer and Barr 2001; Moriceau et al. 2004; Wiedenmayer et al. 2005). Therefore, USV are increased at all ages as the level of anxiety increases (e.g., sustained fear) and inhibited by phasic fear, reflecting a differential USV modulation by anxiety and fear (Jelen et al. 2003).

When animals, including rodents, are confronted with a threat, physiological changes also occur to prepare the organism to cope with and respond to danger. In both adults and infants older than PN10 these modifications of physiological parameters include analgesia (Wiedenmayer and Barr 1998), modification of heart rate, and respiratory rate that either increase or decrease depending on the age of the animal and the threat (Graham and Clifton 1966; Frysztak and Neafsey 1991; Stunden et al. 2001; Fewell et al. 2007), and increase of stress hormone levels (Wiedenmayer et al. 2003; Moriceau et al. 2004).

\section{Ontogenetic development of learned defense responses: emergence of learned fear at PN1O}

Adults learn about threat through pairings of a neutral stimulus (such as odor or tone) with a noxious stimulus (US, such as shock), which produces a learned threat signal, the CS. Specifically, after conditioning, the CS elicits the same kind of behavioral and physiological responses than those observed for the aversive US, or preparatory responses for the predicted occurrence of the threat (i.e., US shock). This threat learning is widely distributed 
in the animal kingdom, but how defensive behavior is measured differs between species (Kalin et al. 2004; Rankin 2004; Tottenham et al. 2011).

This fear learning is dependent upon the amygdala in adults (Fanselow and LeDoux 1999; Phelps 2006; Johansen et al. 2011; Hegoburu et al. 2014) and does not emerge in pups until PN10 (Haroutunian and Campbell 1979; Camp and Rudy 1988; Sullivan et al. 2000a), with functional development of the amygdala (Sullivan et al. 2000a; Raineki et al. 2009). However, the PN10 emergence of threat learning is confined to the olfactory and somatosensory systems and further delayed until PN15-16 when the CS is auditory, and PN17-18 when the CS is visual due to delayed maturation of these sensory systems (Moye and Rudy 1985; Hunt and Campbell 1997). Nevertheless, odor avoidance has been shown in fetal and perinatal rats: these pups learn to avoid an odor provided the learning involves malaise learning induced by either $\mathrm{LiCl}$ or high $(1.0 \mathrm{~mA})$ shock sufficient to induce internal malaise (Haroutunian and Campbell 1979; Smotherman 1982; Kucharski and Spear 1984; Raineki et al. 2009). Thus, odor avoidance learning due to gastric malaise has been demonstrated by using an avoidance task (or disruption of normal behavior) as early as fetal pups (Haroutunian and Campbell 1979; Smotherman 1982; Kucharski and Spear 1984; Raineki et al. 2009) while odor aversion due to fear learning is shown using either avoidance task or freezing in pups older than 9 d old (Sullivan et al. 2000a; Raineki et al. 2009). The divergence in age of expression of malaise and fear learning is due to dependence on different neural networks for learning: the olfactory bulb and piriform cortex are used for malaise learning until pups approach weaning age, while fear learning from PN10 depends upon the later developing amygdala (Shionoya et al. 2006; Raineki et al. 2009). Thus, dependence on the amygdala for two types of learning show divergent ages of functional inclusion of the amygdala in learning.

Similarly to what is observed in response to a predator odor or a shock, suppression of ongoing behavior and USV occurs in response to the learned CS in adults (Jelen et al. 2003; Wöhr et al. 2005; Maren 2008; Shionoya et al. 2013) and allows refined assessment of fear learning in pups at young ages (Pisano et al. 2012; Revillo et al. 2014). In very young pups, with limited motoric ability, learned threat responses have been measured using increased behavioral activity (Sullivan and Wilson 1993; Hunt 1997; Moriceau and Sullivan 2004a; Boulanger Bertolus et al. 2014). However, this behavioral activation reflects the infant's learning of the odor salience rather than its aversive value. Indeed, increases in behavioral activation in response to a learned odor during training are similarly observed whether the animal learns a preference or an aversion to that odor (Moriceau and Sullivan 2004a). Thus, an additional test that permits approach and avoidance behaviors is required to determine hedonic value.

Fear-potentiated startle is also a common measure of learned fear. It uses the subject's reflexive startle to a loud, unexpected sudden noise: when the subject is exposed to a threatening stimulus, the amplitude of the startle increases (Brown et al. 1951; Davis 1979). In pups, the development of fear-potentiated startle has been shown to be delayed compared with the development of acoustic startle (around PN11) (Anderson and Patrick 1934): it emerges at PN23 for visual (Hunt 1999), auditory (Hunt et al. 1994), and olfactory stimuli (Richardson et al. 2000). Thus, fear-potentiated startle can be used in pups beginning around weaning age.

Complementary to behavioral measures, physiological measures have also been widely used to assess learned responses to threat. They have the advantage to be less limited by the motor maturation of the pup and allow fine measure of the temporal response to the threatening CS, although they do not inform about its hedonic value and require the addition of a behavioral test.
Specifically, a change in heart rate in response to a CS can be recorded as a measure of learning (Hunt et al. 1997; Fletcher and Wilson 2002), although based on our understanding of pups' paradoxical responses to threat (i.e., odor preference learning) changes in heart rate cannot distinguish between learned threat and preferences in young pups (<PN10, Fletcher and Wilson 2002). There are also developmental changes in the modulation (increase or decrease) of the heart rate. For example, Hunt et al. (1997) have shown that the presentation of an odor previously paired with a shock triggers an increase in heart rate in 16-d-old rats, while adult rats show a decrease in heart rate to the odor. The developmental switch to adult-like responding appears to occur around weaning: 23 -d-old rats showed a dichotomous pattern of responding, while some pups showed infant-like conditioned responses and some showed adult-like responses (Hunt et al. 1997).

In adults, the respiratory frequency has also been shown to be affected by the rat's emotional arousal (Homma and Masaoka 2008) and aversive conditioning leads to increased respiratory frequency during the presentation of the conditioned stimulus in rats (Frysztak and Neafsey 1991; Shionoya et al. 2013). Interestingly, high temporal resolution analysis of the respiratory rate during the fearful conditioned stimulus presentation revealed the emergence of a temporal pattern linked to the duration of the interval between the onset of the CS and the arrival of the US, suggesting that the animals readily learn the temporal relationships between the two events (Shionoya et al. 2013). Importantly in pups, the respiratory response is also modulated by the duration of CS-US interval, allowing to assert that pups as young as PN12 are able to encode time (Boulanger Bertolus et al. 2014).

In conclusion, the repertoire of behavioral and physiological defense responses, either natural or learned, varies throughout development in relation to the maturation of the animal's sensory and motor abilities, but also on the maturity of the supporting brain structures (Anderson and Patrick 1934; Bolles and Woods 1964; Altman and Sudarshan 1975; Alberts 1984; Hunt and Campbell 1997; Stanton 2000; Pattwell et al. 2013; Perry and Sullivan 2014; Rincón-Cortés and Sullivan 2014). Overall, the measures used to assess threat responses must be adapted to the age of interest. In addition the use of complementary behavioral and physiological variables might be of great help for analyzing the ontogeny of fear.

\section{Neurobiology of threat learning during very early development: Threats fail to engage the amygdala-dependent learning system and instead engage the attachment system}

In the earliest days of life the amygdala is quite immature: neurogenesis is continuing (Bayer 1980), major nuclei subdivision are first discernible around PN7 and stabilizing around PN14 (Bayer 1980; Berdel et al. 1997), synaptic development begins to appear around PN5 and optimized between PN10-20 (Mizukawa et al. 1989; Ryan et al. 2014), and the amygdala undergoes remodeling through adolescence (Koss et al. 2014). This delayed amygdala development might account for the fact that pups younger than PN10 do not learn to fear an odor through odor-shock pairings when moderate shock levels are used $(0.5 \mathrm{~mA})$ and malaise is not produced (Haroutunian and Campbell 1979; Sullivan et al. 1986, 2000a; Camp and Rudy 1988; Roth and Sullivan 2001, 2003, 2005; Moriceau and Sullivan 2004a; Moriceau et al. 2006; Roth et al. 2006; Raineki et al. 2009, 2010b; Upton and Sullivan 2010). Indeed, this conditioning evokes approach responses in a Y-maze and behavioral activation when tested in a small container. In other words, threat learning is not observed before PN10, 
which converges with the emergence of threat responses to natural threats discussed above (Moriceau et al. 2004). Specifically, the odor-shock conditioning procedure produces odor preference with behavioral expression similar to learning induced by pairing the odor with milk, suckling, tactile stimulation (to mimic mother grooming), or maternal care in the nest (Brake 1981; Alberts and May 1984; Sullivan and Leon 1986; Weldon et al. 1991; Raineki et al. 2010b; Roth et al. 2013). Learning to prefer an odor paired with an aversive stimulus occurs in spite of a functional pain system as assessed for instance, through shock induced vocalizations and escape-like behaviors (Small 1899; Anderson and Patrick 1934; Stehouwer and Campbell 1978; Fitzgerald and Gibson 1984; Emerich et al. 1985; Sullivan et al. 2000a; Sevelinges et al. 2011). Importantly, upon further behavioral testing, it became obvious that these myriad conditioning procedures (even those with aversive stimuli) do more than produce an odor preference, they support learning of a new maternal odor, and this odor takes on the properties to support pups' interaction with the mother and are sufficient for enabling nipple attachment (Raineki et al. 2010b; Rincón-Cortés et al. 2015), as would odor pairings with stroking (Pedersen et al. 1982; Raineki et al. 2010b).

We refer to this as the sensitive period for attachment learning and have suggested that this paradoxical preference learning from odor-pain pairings may be designed to ensure the infant always learns to approach the mother (Sullivan et al. 2000a), regardless of the quality of the care. The nest is not a pain free setting for pups: the mother steps on her pups during normal interactions, particularly when entering and leaving the nest (Roth and Sullivan 2005), and this infant learning system can ensure pups will learn an approach response to the mother regardless of its association with pain. Additionally, environmental stress and lack of resources can be associated with poor maternal care and more frequent mother-infant interactions associated with pain (Gilles et al. 1996; Roth and Sullivan 2005; Raineki et al. 2010b; Blaze et al. 2015). Thus, this system can also ensure that the infant learns approach responses to the mother regardless of the quality of care received (Roth and Sullivan 2005; Raineki et al. 2010b). As has been discussed earlier as we consider the development of threat conditioning, this neonatal learning system wanes as pups mature and begin to venture outside the nest (Bolles and Woods 1964; pups begin to walk between PN9 and PN11) and is replaced by learning more characteristic of adults, i.e., the odor-moderate shock pairings readily produces an odor aversion (Camp and Rudy 1988; Sullivan and Wilson 1995; Sullivan et al. 2000a).

There seems to be considerable phylogenetic conservation of this paradoxical pain associated attachment learning system because it has been identified in other species. For example, during imprinting in newly hatched chicks, shock associated with the caregiver (or surrogate) still produces the classic imprinting following behavior, although this learning only occurs during the critical period for imprinting (Pitz and Ross 1961; James and Binks 1963; Kovach and Hess 1963). A similar phenomenon has been shown in nonhuman primates (Seay et al. 1964; Suomi 1978; McCormack et al. 2006; Sanchez 2006) and dogs (Fisher 1955, cited in Rajecki et al. 1978). Finally, attachment to abusive caregivers also occurs in children suggesting that this phenomenon may exist in humans (Morton and Browne 1998; Helfer et al. 1999; Perry 2007).

This odor-shock olfactory classical conditioning, similar to odor paired with other rewards, such as milk and tactile stimulation, causes changes in the olfactory bulb as assessed by c-Fos, 2-DG, and pCreb (Sullivan and Leon 1986; Wilson et al. 1987; Woo et al. 1987; Wilson and Leon 1988; Sullivan et al. 1990; Wilson and Sullivan 1990; Sullivan and Wilson 1991; Johnson et al. 1995; McLean et al. 1999; Yuan et al. 2002; Raineki et al. 2010b). During learning, the infant olfactory bulb principle out- put neurons (mitral and tufted cells) fail to habituate to the odor reward pairings, and continue to show robust responses (Wilson and Sullivan 1992). Controls, such as odor only or random odor-shock groups, fail to learn and habituate after a few presentations. The mitral cell response to odors is maintained by the reward induced norepinephrine (NE) release from the locus coeruleus (LC) onto mitral cells (Sullivan et al. 1992; Wilson and Sullivan 1992; Smith et al. 2009). Manipulation of NE within the bulb using receptor agonists and antagonists or manipulation of the NE source the LC (Shipley et al. 1985; McLean and Shipley 1991) show that NE is causal in supporting both learning induced olfactory bulb changes and the behavior (Sullivan et al. 1989, 1991, 1992, 1994, 2000b; Langdon et al. 1997; Yuan et al. 2003; Moriceau and Sullivan 2004a; Landers and Sullivan 2012; Shakhawat et al. 2012).

High levels of infant NE required to support this learning are available due to unique LC functioning during the neonatal sensitive period, when the LC has a robust and prolonged (20-30 sec) response to infant reward presentation (Nakamura et al. 1987). On the contrary, adult LC responses are measured in milliseconds (Nakamura et al. 1987). The age dependent difference in LC functioning appears to be due to developmental changes in LC autoreceptors with nonfunctional LC inhibitory $\alpha 2$ autoreceptors but robustly functioning $\alpha 1$ excitatory LC autoreceptors during the neonatal sensitive period (Nakamura et al. 1987; Nakamura and Sakaguchi 1990; Sullivan et al. 2000b; Moriceau and Sullivan $2004 \mathrm{~b}$ ). Just as the sensitive period ends, the role of NE becomes more adult-like and rather plays a modulatory role of enhancing or attenuating learning (Selden et al. 1990; Harris and Fitzgerald 1991; Moffat et al. 1993; Sara et al. 1995; Quirarte et al. 1997; Liang 1998; Roozendaal et al. 1999).

Beside the crucial role of the olfactory bulb and NE in the infant learning, several studies have also highlighted the implication of the anterior piriform cortex. The olfactory bulb sends dense projections to the anterior piriform cortex and to a lesser extent to posterior piriform cortex. In addition to the neural changes in the olfactory bulb described above, changes in the anterior piriform cortex are also necessary, and sufficient, for the expression of early odor preference learning (Morrison et al. 2013). Roth and Sullivan (2005) have shown increased $c$-Fos activation in both the olfactory bulb and the anterior piriform cortex, following odor preference training in rat pups. Similarly, Raineki et al (2009) showed that odor-mild shock induced preference was accompanied by selective 2-DG uptake in both the olfactory bulb and anterior piriform cortex.

Therefore, the learned preference to the odor displayed by pups in the sensitive period relies upon a specific network involving the olfactory bulb, and the anterior piriform cortex, with a unique role of $\mathrm{NE}$ and locus coeruleus functioning (Fig. 1, green circuit).

\section{Emergence of amygdala-dependent fear learning}

Fear learning emerges in rat pups around PN10 and is caused by the recruitment of the amygdala during the odor-shock conditioning (Sullivan et al. 2000a; Moriceau and Sullivan 2006; Moriceau et al. 2006; Raineki et al. 2009). Moreover, suppression of the amygdala using muscimol infusions blocks this threat learning (Moriceau and Sullivan 2006), which is consistent with the role of the adult amygdala in threat conditioning (for reviews, see Davis 1992; Fanselow and LeDoux 1999; Cahill et al. 2001; Maren 2001). In addition to amygdala, the posterior piriform cortex also appears to engage in threat learning by the end of the sensitive period (Moriceau et al. 2006; Roth et al. 2006; Raineki et al. 2009), which is also consistent with the adult literature (see below). 

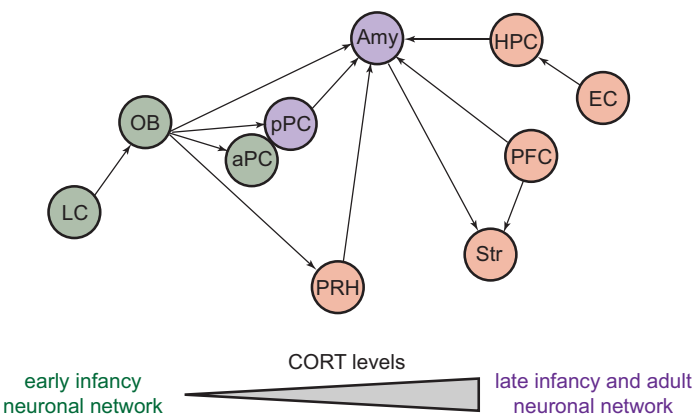

Figure 1. Neuronal networks underlying olfactory threat learning in the early infancy ( $<$ PN10, green), later in infancy ( $>$ PN10, purple), and at adulthood (red is added to purple). The transition from early infancy circuits to late infancy is mediated by the corticosterone (CORT) levels. (LC) locus coeruleus, (OB) olfactory bulb, (aPC) anterior piriform, (pPC) posterior piriform, (Amy) amygdala, (PRH) perirhinal cortex, (Str) striatum, (PFC) prefrontal cortex, (EC) entorhinal cortex, (HPC) hippocampus.

As the rat transitions to adulthood, an increasing number of structures have been shown to take part in olfactory threat learning. The involvement of the amygdala and posterior piriform cortex in learning the association between the odor and the shock has been confirmed at adulthood (Otto et al. 2000; Kilpatrick and Cahill 2003; Hegoburu et al. 2009, 2014; Sacco and Sacchetti 2010; Li 2014): learning of the odor-shock association modifies the response of the amygdala to natural and artificial odors (Funk and Amir 2000; Rosenkranz and Grace 2002; Sevelinges et al. 2004) and decreases its intrinsic excitability (Motanis et al. 2012), while suppressing amygdala functioning impairs olfactory threat learning (Cousens and Otto 1998; Wallace and Rosen 2001; Kilpatrick and Cahill 2003; Walker et al. 2005; Hegoburu et al. 2014). Moreover, learning-induced changes have been described in posterior piriform cortex (Hegoburu et al. 2009; Sevelinges et al. 2004) and lesion or inactivation of this structure was shown to affect long-term memories (Sacco and Sacchetti 2010; Hegoburu et al. 2014). The anterior piriform cortex also seems to be involved in the learning (Barnes et al. 2011; Wilson and Sullivan 2011), as the post-training disruption of its functioning leads to generalization of the learning. Indeed using a discriminative odor fear conditioning paradigm, the authors showed that when tested $24 \mathrm{~h}$ later, control rats presented a selective freezing response to the odor associated with a shock during training, while rats infused with baclofen in the anterior piriform cortex showed freezing to both reinforced and nonreinforced odors (Barnes and Wilson 2014).

In adults, beside the amygdala and piriform cortex, numerous other structures have been shown to exhibit changes following olfactory fear conditioning, from the earliest stages of olfactory processing (i.e., the olfactory receptors) (Jones et al. 2008; Kass et al. 2013), to associative cortices such as the entorhinal and perirhinal cortices (Herzog and Otto 1997; Funk and Amir 2000; Otto et al. 2000; Jones et al. 2007), but also structures such as the basal ganglia (Boulanger Bertolus et al. 2014) and medial prefrontal cortex (Funk and Amir 2000; Kim and Richardson 2010; Sotres-Bayon and Quirk 2010). The hippocampus and the prefrontal cortex (PFC) have also been involved in olfactory fear conditioning, although not in the learning of the odor-shock association per se. For example, the hippocampus has been shown to be involved both in the learning of an unimodal olfactory context in which odors are used to differentiate otherwise identical conditioning contexts (Otto and Poon 2006) and in learning the multimodal context in an olfactory fear conditioning paradigm (Raineki et al. 2010a).
In infancy, these structures slowly mature. Little is known about the functional maturation of the entorhinal and perirhinal cortices and of the basal ganglia, especially concerning their participation in odor fear conditioning at early ages. In contrast, the functional maturation of the hippocampus has been more investigated. For example the late developing hippocampus, with efferent connectivity to other brain areas occurring in the second week of life (Crain et al. 1973), does not support contextual learning until after weaning (PN21-23; Rudy et al. 1987; Rudy 1993, 1994; Rudy and Morledge 1994; Ivkovich et al. 2000), which has been causally linked to the emergence of the hippocampus (Raineki et al. 2010a). However, other forms of hippocampal-dependent learning occur at an earlier age (for review, see Stanton 2000). Furthermore, it is possible for this infant hippocampal-dependent learning to occur and not be expressed until a later time in life (Pattwell et al. 2011; Poulos et al. 2014).

To summarize, in infancy, olfactory threat learning depends upon the amygdala and the posterior piriform cortex (Fig. 1, purple circuit). At adulthood, other structures get involved in the conditioning, likely supporting the learning but also its modulation and contextualization (Fig. 1, red circuit).

\section{Corticosterone is critical in the developmental onset of amygdala-dependent threat learning and social modulation of its levels switches fear learning on and off}

The transition from infant to adult-like neural network of olfactory threat conditioning initially seemed quite abrupt in its emergence at PN10 (Sullivan et al. 2000a). While we originally thought the amygdala's lack of participation in younger pups' odor-shock conditioning/preference learning was due to the amygdala's immaturity, this was not the case. More careful analysis showed that the level of corticosterone (CORT) is critical in the emergence of pups conditioning, not the maturity of the amygdala. Indeed, at PN10, the endogenous level of CORT is sufficient to permit amygdala plasticity thus enabling pups' amygdala to participate in fear conditioning. Blood levels of pups' CORT correlate with whether or not pups learn threat, but more importantly, manipulation of CORT can switch fear leaning on or off (Moriceau et al. 2006; Moriceau and Sullivan 2006; Shionoya et al. 2007). Specifically, causation for the role of CORT in pup threat conditioning was demonstrated by manipulation of CORT through systemic injections or by intra-amygdala infusions during fear conditioning: increasing CORT supported learning and amygdala participation, while blocking CORT via system or intra-amygdala infusion blocked fear learning (Moriceau et al. 2006). The ability of CORT to control learning ends at PN15 (Upton and Sullivan 2010).

The ability of low CORT to block threat learning is unique to infancy, although CORT does play a modulatory role in adult fear and avoidance conditioning by increasing or decreasing learning strength (Pugh et al. 1997; Ferry et al. 1999; Hui et al. 2004; McGaugh 2004).

In pups, the mother controls pups' CORT levels (Stanton and Levine 1990; Suchecki et al. 1993), and through this mechanism the mother can block pups' amygdala-dependent fear learning (Wiedenmayer et al. 2003; Moriceau and Sullivan 2006). Specifically, in pups, maternal presence or just sensory stimulation from the mother (i.e., her odor, touch) maintains pups' low CORT levels and blocks CORT increase in response to shock (Levin et al. 1976; Stanton et al. 1987; Moriceau and Sullivan 2006; Shionoya et al. 2007; Gunnar et al. 2015). Indeed, when the pups are separated from the mother and lose this regulation, pups' CORT begins to rise in about an hour. This process of the mother blocking stress induced CORT release is called social buffering and 
occurs in many species (Hennessy et al. 2009; Gee et al. 2014; Hostinar et al. 2014).

CORT control by the mother has a direct impact on infant conditioning by switching whether infants will learn avoidance or attachment. One potential mechanism for maternal modulation of pup CORT levels and odor learning is through its influence on the neural and noradrenergic activity of the paraventricular nucleus of the hypothalamus (PVN), a brain area important for contextspecific responses to diverse stressors and the site of CORT and NE interaction. Maternal presence attenuates both PVN neural activity and PVN NE levels during odor-shock conditioning (Shionoya et al. 2007). Furthermore, intra-PVN NE microinfusions initiates fear learning even in the presence of the mother, while blocking the NE receptors overrides the maternal blockade of fear learning. Together these data suggest that maternal control over pup learning acts through attenuation of PVN NE to reduce the CORT required for pup odor aversion learning. This dual learning of either approach or avoidance controlled by the mother highlights pups' continued maternal dependence for nursing, that requires approach, while enabling aversion learning outside the nest to prepare for pups' future independent living.

While the buffering of infant responses by the mother is the most robust and thoroughly investigated form of social buffering, social buffering of fear is also observed at older ages and in adult animals. As the animal matures, peers also become potent sources of social buffering (Hennessy et al. 2009). For instance, Terranova et al. (1999) reported that in periadolescent rats (PN35), the presence of a conspecific exerts a significant buffering effect on the novelty-induced increase in CORT levels. In adult rats, Kiyokawa et al. (2014) showed that the presence of a conspecific suppresses the learned fear response and HPA axis response to a level similar to those observed in the nonconditioned subjects. Interestingly, as observed for the mother-pup dyad, olfactory signals mediate the social buffering of conditioned fear responses (Takahashi et al. 2013; Kiyokawa 2015).

This social buffering at all ages of development also occurs in nonhuman primates and humans (Hennessy et al. 2009; Gunnar et al. 2015). In infancy, the parent can buffer the stress response of the infant (Smotherman et al. 1979; Gunnar and Donzella 2002). At adulthood, social groups reduce the HPA axis response to stress depending on the nature of the social bond (Stanton et al. 1985; Phillips et al. 2009).

\section{Social transmission of fear: mother to infant}

In contrast to its role in social buffering, maternal presence can also induce social transmission of fear learning to its progeny. In social fear learning, an organism learns fear through exposure to a conspecific expressing fear to a discrete conditioned stimulus. Debiec and Sullivan (2014) showed that maternal fear responses to a conditioned fear odor are sufficient to induce robust fear learning throughout infancy as early as PN6, with long-term retention. The transmission of fear from the mother to the pups is mediated by an alarm odor emitted by the frightened mother. Assessment of the involved mechanisms showed that maternal fear expression increases pups' stress hormone corticosterone and amygdala activation to induce this cue-specific fear learning (see Fig. 2). Suppressing pups' amygdala or preventing pups from mounting a stress response blocked this fear learning. Specific fears may thus be transferred across generations through maternal emotional communication and infant's associative learning mechanisms.

Social transmission of fear was also reported in adult rats. For instance, rats exposed to a novel tone in the presence of a cagemate previously fear conditioned to that same tone, selectively showed increased freezing to the stimulus the next day (Bruchey et al. 2010). This suggests that, during memory retrieval, fear of a stimulus can be socially transmitted to a cage-mate. Similarly, Knapska and colleagues carried out an experiment in which rats were housed in pairs, and one of the two was fear conditioned to a context. After interacting with the conditioned cage-mate in the homecage, the remaining rat shows enhanced fear learning compared with controls when later conditioned (Knapska et al. 2010) and increased c-Fos labeling in the amygdala (Knapska et al. 2006). In rats, it has been shown that such social transmission of fear is mediated by alarm pheromones released from perianal region of the pheromone-donor rats (Kiyokawa et al. 2004) and detected by the vomeronasal organ and the Grueneberg ganglion of the receiver rat (Brechbühl et al. 2008; Kiyokawa et al. 2013; Kiyokawa 2015).

In humans, social transmission of fear has been also shown from the mother to her child: the infant regulates its behavior according to the caregiver's emotional expression. This is known as social referencing (Frith 2008). Besides, infants can learn from the pathological fear of their mothers (Murray et al. 2008; Bosquet Enlow et al. 2011). In adult humans, social transmission of anxiety has also been demonstrated: humans can discriminate stressrelated bodily odors and such odors increase the anxiety of the smelling subject (Ackerl et al. 2002; Albrecht et al. 2011).

Therefore, throughout the animal's life, social environment can modulate fear responses to a threatening event, mainly through its influence on HPA axis to reduce stress hormone release. However, the social partner that can socially buffer the stress response changes with development, with the mother playing a major role during infancy, and peers/conspecifics being more potent sources of social buffering as the animal transitions to adulthood.

\section{Conclusion}

Learning about threat is a vital evolutionary ability shared throughout the phylogeny. However, in altricial species, such learning would be extremely detrimental if it occurred within 
the nest where the only source of threat is also the only source of food and warmth, i.e., the caregiver. We reviewed the ontogeny of threat learning and highlighted the switch between learned preference and learned aversion as the pup matures and ventures outside the nest. Infant and adult learning are supported by distinct neuronal networks and the transition between these networks is under the influence of corticosterone levels. Importantly, the mother in infancy has the ability to modulate stress hormone levels, allowing the complete switch between threat and preference learning. While social buffering of CORT occurs at all ages and can modify fear learning in adults, its ability to block fear learning is unique to infancy (Hostinar et al. 2014).

The characteristics of fear learning in infancy described here in rats have strong parallels in humans. Indeed, attachment to an abusive caregiver as well as parental modulation of fear have been extensively described in human infants, reinforcing the idea that these phenomena are particularly suitable for translational studies.

\section{Acknowledgments}

This work was supported by grants DC009910, MH091451, HD083217 (R.M.S.), by Partner University Fund Emotion \& Time (J.B.B., A.M.M., R.M.S.), LIA CNRS-NYU LearnEmoTime (J.B.B., A.M.M., R.M.S.), and the LABEX CORTEX (ANR-11LABX-0042) of Université de Lyon, within the program "Investissements d'avenir" (ANR-11-IDEX-0007) operated by the French National Research Agency (ANR) (J.B.B., A.M.M.).

\section{References}

Ackerl K, Atzmueller M, Grammer K. 2002. The scent of fear. Neuro Endocrinol Lett 23: 79-84.

Alberts JR. 1984. Sensory-perceptual development in the Norway rat: A view toward comparative studies. In Comparative perspectives on the development of memory (ed. Kail R, Spear NE), pp 65-101. Lawrence Erlbaum Associates, Hillsdale, NJ.

Alberts JR, May B. 1984. Nonnutritive, thermotactile induction of filial huddling in rat pups. Dev Psychobiol 17: 161-181.

Albrecht J, Demmel M, Schöpf V, Kleemann AM, Kopietz R, May J, Schreder T, Zernecke R, Brückmann H, Wiesmann M. 2011. Smelling chemosensory signals of males in anxious versus nonanxious condition increases state anxiety of female subjects. Chem Senses 36: $19-27$.

Allin JT, Banks EM. 1971. Effects of temperature on ultrasound production by infant albino rats. Dev Psychobiol 4: 149-156.

Altman J, Sudarshan K. 1975. Postnatal development of locomotion in the laboratory rat. Anim Behav 23: 896-920.

Anagnostaras SG, Josselyn SA, Frankland PW, Silva AJ. 2000. Computer-assisted behavioral assessment of Pavlovian fear conditioning in mice. Learn Mem 7: 58-72.

Anderson AC, Patrick JR. 1934. Some early behavior patterns in the white rat. Psychol Rev 41: 480-496.

Bader PL, Faizi M, Kim LH, Owen SF, Tadross MR, Alfa RW, Bett GCL, Tsien RW, Rasmusson RL, Shamloo M. 2011. Mouse model of Timothy syndrome recapitulates triad of autistic traits. Proc Natl Acad Sci 108: 15432-15437.

Barnes DC, Wilson DA. 2014. Slow-wave sleep-imposed replay modulates both strength and precision of memory. J Neurosci 34: 5134-5142.

Barnes DC, Chapuis J, Chaudhury D, Wilson DA. 2011. Odor fear conditioning modifies piriform cortex local field potentials both during conditioning and during post-conditioning sleep. PLoS One 6: e18130.

Barr GA, Perry RE, Sullivan RM. 2015. Long and short term effects of the mother's presence during noxious stimulation in the infant rat. In 2015 Neuroscience Meeting Planner, Chicago, IL. http://www .abstractsonline.com/Plan/ViewAbstract.aspx?sKey=06236e9c-145a4c1e-9ce9-e45431705722\&cKey=ec1dfff4-138d-495c-a85ed830337d6aa8\&mKey=d0ff4555-8574-4fbb-b9d4-04eec8ba0c84.

Bayer SA. 1980. Quantitative 3H-thymidine radiographic analyses of neurogenesis on the rat amygdala. J Comp Neurol 194: 845-875.

Berdel B, Moryś J, Maciejewska B. 1997. Neuronal changes in the basolateral complex during development of the amygdala of the ratfn2. Int J Dev Neurosci 15: 755-765.
Blanchard RJ, Blanchard DC. 1969a. Crouching as an index of fear. J Comp Physiol Psychol 67: 370-375.

Blanchard RJ, Blanchard DC. 1969b. Passive and active reactions to fear-eliciting stimuli. J Comp Physiol Psychol 68: 129-135.

Blanchard RJ, Blanchard DC. 1989. Attack and defense in rodents as ethoexperimental models for the study of emotion. Prog Neuropsychopharmacol Biol Psychiatry 13: S3-S14.

Blanchard RJ, Blanchard DC, Rodgers J, Weiss SM. 1990. The characterization and modelling of antipredator defensive behavior. Neurosci Biobehav Rev 14: 463-472.

Blanchard RJ, Blanchard DC, Agullana R, Weiss SM. 1991. Twenty-two kHz alarm cries to presentation of a predator, by laboratory rats living in visible burrow systems. Physiol Behav 50: 967-972.

Blaze J, Asok A, Roth TL. 2015. The long-term impact of adverse caregiving environments on epigenetic modifications and telomeres. Front Behav Neurosci 9: 79.

Blumberg MS, Alberts JR. 1990. Ultrasonic vocalizations by rat pups in the cold: an acoustic by-product of laryngeal braking? Behav Neurosci 104: 808 .

Bolles RC. 1970. Species-specific defense reactions and avoidance learning. Psychol Rev 77: 32-48.

Bolles RC, Collier AC. 1976. The effect of predictive cues on freezing in rats. Anim Learn Behav 4: 6-8.

Bolles RC, Fanselow MS. 1980. A perceptual-defensive-recuperative model of fear and pain. Behav Brain Sci 3: 291-301.

Bolles RC, Woods PJ. 1964. The ontogeny of behaviour in the albino rat. Anim Behav 12: 427-441.

Bosquet Enlow M, Kitts RL, Blood E, Bizarro A, Hofmeister M, Wright RJ. 2011. Maternal posttraumatic stress symptoms and infant emotional reactivity and emotion regulation. Infant Behav Dev 34: 487-503.

Boulanger Bertolus J, Hegoburu C, Ahers JL, Londen E, Rousselot J, Szyba K, Thévenet M, Sullivan-Wilson TA, Doyère V, Sullivan RM, et al. 2014. Infant rats can learn time intervals before the maturation of the striatum: evidence from odor fear conditioning. Front Behav Neurosci 8: 176.

Boulanger Bertolus J, Rincón-Cortés M, Sullivan RM, Mouly A-M. 2015. Ontogeny of ultrasonic vocalization and respiratory responses to an aversive event in rats. In 2015 Neuroscience Meeting Planner, Chicago, IL. http://www.abstractsonline.com/Plan/ViewAbstract.aspx?sKey= 8fbbb6eb-f987-4961-a645-1a996e542f84\&cKey=bc3700ef-310a-4d78b03f-71a18c1b91da\&mKey=d0ff4555-8574-4fbb-b9d4-04eec8ba0c84.

Brake SC. 1981. Suckling infant rats learn a preference for a novel olfactory stimulus paired with milk delivery. Science 211: 506-508.

Branchi I, Santucci D, Alleva E. 2001. Ultrasonic vocalisation emitted by infant rodents: a tool for assessment of neurobehavioural development. Behav Brain Res 125: 49-56.

Brechbühl J, Klaey M, Broillet M-C. 2008. Grueneberg ganglion cells mediate alarm pheromone detection in mice. Science 321: 1092-1095.

Bronstein PM, Hirsch SM. 1976. Ontogeny of defensive reactions in Norway rats. J Comp Physiol Psychol 90: 620-629.

Brown JS, Kalish HI, Farber EI. 1951. Conditioned fear as revealed by magnitude of startle response to an auditory stimulus. J Exp Psychol 41: $317-328$.

Bruchey AK, Jones CE, Monfils M-H. 2010. Fear conditioning by-proxy: social transmission of fear during memory retrieval. Behav Brain Res 214: $80-84$.

Brudzynski SM, Ociepa D. 1992. Ultrasonic vocalization of laboratory rats in response to handling and touch. Physiol Behav 52: 655-660.

Cahill L, McGaugh JL, Weinberger NM. 2001. The neurobiology of learning and memory: some reminders to remember. Trends Neurosci 24: $578-581$.

Callaghan BL, Sullivan RM, Howell B, Tottenham N. 2014. The international society for developmental psychobiology Sackler symposium: early adversity and the maturation of emotion circuits - A cross-species analysis. Dev Psychobiol 56: 1635-1650.

Camp LL, Rudy JW. 1988. Changes in the categorization of appetitive and aversive events during postnatal development of the rat. Dev Psychobiol 21: $25-42$.

Collier AC, Bolles RC. 1980. The ontogenesis of defensive reactions to shock in preweanling rats. Dev Psychobiol 13: 141-150.

Cornwell-Jones C, Sobrian SK. 1977. Development of odor-guided behavior in Wistar and Spraque-Dawley rat pups. Physiol Behav 19: 685-688.

Coureaud G, Moncomble A-S, Montigny D, Dewas M, Perrier G, Schaal B. 2006. A pheromone that rapidly promotes learning in the newborn. Curr Biol 16: 1956-1961.

Cousens G, Otto T. 1998. Both pre- and posttraining excitotoxic lesions of the basolateral amygdala abolish the expression of olfactory and contextual fear conditioning. Behav Neurosci 112: 1092-1103.

Crain B, Cotman C, Taylor D, Lynch G. 1973. A quantitative electron microscopic study of synaptogenesis in the dentate gyrus of the rat. Brain Res 63: 195-204. 
Cuomo V, Cagiano R, De Salvia MA, Maselli MA, Renna G, Racagni G. 1988. Ultrasonic vocalization in response to unavoidable aversive stimuli in rats: effects of benzodiazepines. Life Sci 43: 485-491.

Davis M. 1979. Diazepam and flurazepam: Effects on conditioned fear as measured with the potentiated startle paradigm. Psychopharmacology (Berl) 62: 1-7.

Davis M. 1989. Neural systems involved in fear-potentiated startle. Ann N Y Acad Sci 563: 165-183.

Davis M. 1992. The role of the amygdala in fear and anxiety. Annu Rev Neurosci 15: $353-375$

Debiec J, Sullivan RM. 2014. Intergenerational transmission of emotional trauma through amygdala-dependent mother-to-infant transfer of specific fear. Proc Natl Acad Sci 111: 12222-12227.

Delgado MR, Olsson A, Phelps EA. 2006. Extending animal models of fear conditioning to humans. Biol Psychol 73: 39-48.

Drew MR, Zupan B, Cooke A, Couvillon PA, Balsam PD. 2005. Temporal control of conditioned responding in goldfish. J Exp Psychol Anim Behav Process 31: 31-9.

Emerich DF, Scalzo FM, Enters EK, Spear NE, Spear LP. 1985. Effects of 6-hydroxydopamine-induced catecholamine depletion on shock-precipitated wall climbing of infant rat pups. Dev Psychobiol 18: 215-227.

Fanselow MS. 1994. Neural organization of the defensive behavior system responsible for fear. Psychon Bull Rev 1: 429-438.

Fanselow MS, LeDoux JE. 1999. Why we think plasticity underlying Pavlovian fear conditioning occurs in the basolateral amygdala. Neuron 23: $229-232$.

Ferry B, Roozendaal B, McGaugh JL. 1999. Role of norepinephrine in mediating stress hormone regulation of long-term memory storage: a critical involvement of the amygdala. Biol Psychiatry 46: 1140-1152.

Fewell JE, Zhang C, Gillis AM. 2007. Influence of adenosine A1-receptor blockade and vagotomy on the gasping and heart rate response to hypoxia in rats during early postnatal maturation. J Appl Physiol 103: $1234-1241$

Fisher AE. 1955. "The effects of differential early treatment on the social and exploratory behavior of puppies." Doctoral dissertation, Pennsylvania State University.

Fitzgerald M, Gibson S. 1984. The postnatal physiological and neurochemical development of peripheral sensory $\mathrm{C}$ fibres. Neuroscience 13: 933-944.

Fletcher ML, Wilson DA. 2002. Experience modifies olfactory acuity: acetylcholine-dependent learning decreases behavioral generalization between similar odorants. J Neurosci 22: RC201.

Frith CD. 2008. Social cognition. Philos Trans R Soc Lond B Biol Sci 363: 2033-2039.

Frysztak RJ, Neafsey EJ. 1991. The effect of medial frontal cortex lesions on respiration, "freezing," and ultrasonic vocalizations during conditioned emotional responses in rats. Cereb Cortex 1: 418-425.

Funk D, Amir S. 2000. Enhanced Fos expression within the primary olfactory and limbic pathways induced by an aversive conditioned odor stimulus. Neuroscience 98: 403-406.

Gandal MJ, Edgar JC, Ehrlichman RS, Mehta M, Roberts TPL, Siegel SJ. 2010. Validating $\gamma$ oscillations and delayed auditory responses as translational biomarkers of autism. Biol Psychiatry 68: 1100-1106.

Gardner CR. 1985. Distress vocalization in rat pups a simple screening method for anxiolytic drugs. J Pharmacol Methods 14: 181-187.

Gee DG, Gabard-Durnam L, Telzer EH, Humphreys KL, Goff B, Shapiro M, Flannery J, Lumian DS, Fareri DS, Caldera C, et al. 2014. Maternal buffering of human amygdala-prefrontal circuitry during childhood but not during adolescence. Psychol Sci 25: 2067-2078.

Gilles EE, Schultz L, Baram TZ. 1996. Abnormal corticosterone regulation in an immature rat model of continuous chronic stress. Pediatr Neurol 15: $114-119$.

Graham FK, Clifton RK. 1966. Heart-rate change as a component of the orienting response. Psychol Bull 65: 305-320.

Gunnar MR, Donzella B. 2002. Social regulation of the cortisol levels in early human development. Psychoneuroendocrinology 27: 199-220.

Gunnar MR, Hostinar CE, Sanchez MM, Tottenham N, Sullivan RM. 2015. Parental buffering of fear and stress neurobiology: reviewing parallels across rodent, monkey, and human models. Soc Neurosci 10: 474-478.

Haroutunian V, Campbell BA. 1979. Emergence of interoceptive and exteroceptive control of behavior in rats. Science 205: 927-929.

Harris GC, Fitzgerald RD. 1991. Locus coeruleus involvement in the learning of classically conditioned bradycardia. J Neurosci 11: 2314-2320.

Hegoburu C, Sevelinges Y, Thévenet M, Gervais R, Parrot S, Mouly A-M. 2009. Differential dynamics of amino acid release in the amygdala and olfactory cortex during odor fear acquisition as revealed with simultaneous high temporal resolution microdialysis. Learn Mem 16: 687-697.

Hegoburu C, Shionoya K, Garcia S, Messaoudi B, Thevenet M, Mouly A-M. 2011. The RUB cage: respiration-ultrasonic vocalizations-behavior acquisition setup for assessing emotional memory in rats. Front Behav Neurosci 5: 25.

Hegoburu C, Parrot S, Ferreira G, Mouly A-M. 2014. Differential involvement of amygdala and cortical NMDA receptors activation upon encoding in odor fear memory. Learn Mem 21: 651-655.

Helfer ME, Kempe RS, Krugman RD. 1999. The Battered Child. University of Chicago Press, Chicago, IL.

Hennessy MB, Kaiser S, Sachser N. 2009. Social buffering of the stress response: diversity, mechanisms, and functions. Front Neuroendocrinol 30: $470-482$.

Herzog C, Otto T. 1997. Odor-guided fear conditioning in rats: 2. Lesions of the anterior perirhinal cortex disrupt fear conditioned to the explicit conditioned stimulus but not to the training context. Behav Neurosci 111: $1265-1272$.

Hofer MA, Shair H. 1978. Ultrasonic vocalization during social interaction and isolation in 2-week-old rats. Dev Psychobiol 11: 495-504.

Hofer MA, Shair HN, Brunelli SA. 2001. Ultrasonic vocalizations in rat and mouse pups. In Current Protocols in Neuroscience, John Wiley \& Sons, New York.

Homma I, Masaoka Y. 2008. Breathing rhythms and emotions. Exp Physiol 93: $1011-1021$.

Hostinar CE, Sullivan RM, Gunnar MR. 2014. Psychobiological mechanisms underlying the social buffering of the hypothalamicpituitary-adrenocortical axis: a review of animal models and human studies across development. Psychol Bull 140: 256-282.

Hui GK, Figueroa IR, Poytress BS, Roozendaal B, McGaugh JL, Weinberger NM. 2004. Memory enhancement of classical fear conditioning by post-training injections of corticosterone in rats. Neurobiol Learn Mem 81: 67-74.

Hunt PS. 1997. Retention of conditioned autonomic and behavioral responses in preweanling rats: forgetting and reinstatement. Anim Learn Behav 25: 301-311.

Hunt PS. 1999. A further investigation of the developmental emergence of fear-potentiated startle in rats. Dev Psychobiol 34: 281-291.

Hunt PS, Campbell BA. 1997. Developmental dissociation of the components of conditioned fear. In Learning, motivation, and cognition: The functional behaviorism of Robert C. Bolles (ed. Bouton ME, Fanselow MS), pp. 53-74. American Psychological Association, Washington, DC.

Hunt PS, Richardson R, Campbell BA. 1994. Delayed development of fear-potentiated startle in rats. Behav Neurosci 108: 69-80.

Hunt PS, Hess MF, Campbell BA. 1997. Conditioned cardiac and behavioral response topography to an olfactory CS dissociates with age. Anim Learn Behav 25: 53-61.

Insel TR, Hill JL, Mayor RB. 1986. Rat pup ultrasonic isolation calls: possible mediation by the benzodiazepine receptor complex. Pharmacol Biochem Behav 24: 1263-1267.

Ivkovich D, Paczkowski CM, Stanton ME. 2000. Ontogeny of delay versus trace eyeblink conditioning in the rat. Dev Psychobiol 36: 148-160.

James H, Binks C. 1963. Escape and avoidance learning in newly hatched domestic chicks. Science 139: 1293-1294.

Jelen P, Soltysik S, Zagrodzka J. 2003. 22-kHz Ultrasonic vocalization in rats as an index of anxiety but not fear: behavioral and pharmacological modulation of affective state. Behav Brain Res 141: 63-72.

Johansen JP, Cain CK, Ostroff LE, LeDoux JE. 2011. Molecular mechanisms of fear learning and memory. Cell 147: 509-524.

Johanson IB, Teicher MH. 1980. Classical conditioning of an odor preference in 3-day-old rats. Behav Neural Biol 29: 132-136.

Johnson BA, Woo CC, Duong H, Nguyen V, Leon M. 1995. A learned odor evokes an enhanced Fos-like glomerular response in the olfactory bulb of young rats. Brain Res 699: 192-200.

Jones SV, Stanek-Rattiner L, Davis M, Ressler KJ. 2007. Differential regional expression of brain-derived neurotrophic factor following olfactory fear learning. Learn Mem 14: 816-820.

Jones SV, Choi DC, Davis M, Ressler KJ. 2008. Learning-dependent structural plasticity in the adult olfactory pathway. J Neurosci $\mathbf{2 8}$ $13106-13111$.

Kalin NH, Shelton SE, Davidson RJ. 2004. The role of the central nucleus of the amygdala in mediating fear and anxiety in the primate. J Neurosci 24: 5506-5515.

Kaltwasser MT. 1990. Startle-inducing acoustic stimuli evoke ultrasonic vocalization in the rat. Physiol Behav 48: 13-17.

Kass MD, Rosenthal MC, Pottackal J, McGann JP. 2013. Fear learning enhances neural responses to threat-predictive sensory stimuli. Science 342: $1389-1392$.

Kilpatrick L, Cahill L. 2003. Modulation of memory consolidation for olfactory learning by reversible inactivation of the basolateral amygdala. Behav Neurosci 117: 184-188.

Kim JH, Richardson R. 2010. New findings on extinction of conditioned fear early in development: theoretical and clinical implications. Biol Psychiatry 67: 297-303. 
Kiyokawa Y. 2015. Social odors: alarm pheromones and social buffering. In Current Topics in Behavioral Neurosciences, pp. 1-19, Springer, Berlin, Heidelberg. http://link.springer.com/chapter/10.1007/7854_2015_ 406.

Kiyokawa Y, Kikusui T, Takeuchi Y, Mori Y. 2004. Alarm pheromones with different functions are released from different regions of the body surface of male rats. Chem Senses 29: 35-40.

Kiyokawa Y, Kodama Y, Kubota T, Takeuchi Y, Mori Y. 2013. Alarm pheromone is detected by the vomeronasal organ in male rats. Chem Senses 38: 661-668.

Kiyokawa Y, Hiroshima S, Takeuchi Y, Mori Y. 2014. Social buffering reduces male rats' behavioral and corticosterone responses to a conditioned stimulus. Horm Behav 65: 114-118.

Kleitman N, Satinoff E. 1982. Thermoregulatory behavior in rat pups from birth to weaning. Physiol Behav 29: 537-541.

Knapska E, Nikolaev E, Boguszewski P, Walasek G, Blaszczyk J, Kaczmarek L, Werka T. 2006. Between-subject transfer of emotional information evokes specific pattern of amygdala activation. Proc Natl Acad Sci 103: $3858-3862$.

Knapska E, Mikosz M, Werka T, Maren S. 2010. Social modulation of learning in rats. Learn Mem 17: 35-42.

Koss WA, Belden CE, Hristov AD, Juraska JM. 2014. Dendritic remodeling in the adolescent medial prefrontal cortex and the basolateral amygdala of male and female rats. Synapse 68: 61-72.

Kovach JK, Hess EH. 1963. Imprinting: effects of painful stimulation upon the following response. J Comp Physiol Psychol 56: 461-464.

Kucharski D, Spear NE. 1984. Conditioning of aversion to an odor paired with peripheral shock in the developing rat. Dev Psychobiol 17: 465-479.

Landers MS, Sullivan RM. 2012. The development and neurobiology of infant attachment and fear. Dev Neurosci 34: 101-114

Langdon PE, Harley CW, McLean JH. 1997. Increased $\beta$ adrenoceptor activation overcomes conditioned olfactory learning deficits induced by serotonin depletion. Dev Brain Res 102: 291-293.

LeDoux JE. 2000. Emotion circuits in the Brain. Annu Rev Neurosci 23: $155-184$.

Levin R, Fitzpatrick KM, Levine S. 1976. Maternal influences on the ontogeny of basal levels of plasma corticosterone in the rat. Horm Behav 7: $41-48$.

Li W. 2014. Learning to smell danger: acquired associative representation of threat in the olfactory cortex. Front Behav Neurosci 8: 98.

Liang KC. 1998. Pretraining infusion of DSP-4 into the amygdala impaired retention in the inhibitory avoidance task: involvement of norepinephrine but not serotonin in memory facilitation. Chin J Physiol 41: $223-233$.

Longo N, Milstein S, Bitterman ME. 1962. Classical conditioning in the pigeon: exploratory studies of partial reinforcement. J Comp Physiol Psychol 55: 983-986.

Lore R, Flannelly K, Farina P. 1976. Ultrasounds produced by rats accompany decreases in intraspecific fighting. Aggress Behav 2: $175-181$.

Maren S. 2001. Neurobiology of Pavlovian fear conditioning. Annu Rev Neurosci 24: 897-931.

Maren S. 2008. Pavlovian fear conditioning as a behavioral assay for hippocampus and amygdala function: cautions and caveats. Eur $J$ Neurosci 28: 1661-1666.

McCormack K, Sanchez MM, Bardi M, Maestripieri D. 2006. Maternal care patterns and behavioral development of rhesus macaque abused infants in the first 6 months of life. Dev Psychobiol 48: 537-550.

McGaugh JL. 2004. The amygdala modulates the consolidation of memories of emotionally arousing experiences. Annu Rev Neurosci 27: $1-28$.

McLean JH, Shipley MT. 1991. Postnatal development of the noradrenergic projection from locus coeruleus to the olfactory bulb in the rat. J Comp Neurol 304: 467-477.

McLean JH, Harley CW, Darby-King A, Yuan Q. 1999. pCREB in the neonate rat olfactory bulb is selectively and transiently increased by odor preference-conditioned training. Learn Mem 6: 608-618.

Mennella JA, Jagnow CP, Beauchamp GK. 2001. Prenatal and postnatal flavor learning by human infants. Pediatrics 107: e88.

Mizukawa K, Tseng I-M, Otsuka N. 1989. Quantitative electron microscopic analysis of postnatal development of zinc-positive nerve endings in the rat amygdala using Timm's sulphide silver technique. Dev Brain Res 50: 197-203.

Moffat SD, Suh EJ, Fleming AS. 1993. Noradrenergic involvement in the consolidation of maternal experience in postpartum rats. Physiol Behav 53: $805-811$.

Moriceau S, Sullivan RM. 2004a. Corticosterone influences on mammalian neonatal sensitive-period learning. Behav Neurosci 118: 274-281.

Moriceau S, Sullivan RM. 2004b. Unique neural circuitry for neonatal olfactory learning. J Neurosci 24: 1182-1189.
Moriceau S, Sullivan RM. 2006. Maternal presence serves as a switch between learning fear and attraction in infancy. Nat Neurosci 9: 1004-1006.

Moriceau S, Roth TL, Okotoghaide T, Sullivan RM. 2004. Corticosterone controls the developmental emergence of fear and amygdala function to predator odors in infant rat pups. Int J Dev Neurosci 22: 415-422.

Moriceau S, Wilson DA, Levine S, Sullivan RM. 2006. Dual circuitry for odor-shock conditioning during infancy: corticosterone switches between fear and attraction via amygdala. J Neurosci 26: 6737-6748.

Morrison GL, Fontaine CJ, Harley CW, Yuan Q. 2013. A role for the anterior piriform cortex in early odor preference learning: evidence for multiple olfactory learning structures in the rat pup. J Neurophysiol 110: $141-152$.

Morton N, Browne KD. 1998. Theory and observation of attachment and its relation to child maltreatment: a review. Child Abuse Negl 22: 1093-1104.

Motanis H, Maroun M, Barkai E. 2012. Learning-induced bidirectional plasticity of intrinsic neuronal excitability reflects the valence of the outcome. Cereb Cortex 24: 1075-1087.

Moye TB, Rudy JW. 1985. Ontogenesis of learning: VI. Learned and unlearned responses to visual stimulation in the infant hooded rat. Dev Psychobiol 18: $395-409$.

Murray L, De Rosnay M, Pearson J, Bergeron C, Schofield E, Royal-Lawson M, Cooper PJ. 2008. Intergenerational transmission of social anxiety: the role of social referencing processes in infancy. Child Dev 79: 1049-1064

Nakamura S, Sakaguchi T. 1990. Development and plasticity of the locus coeruleus: a review of recent physiological and pharmacological experimentation. Prog Neurobiol 34: 505-526.

Nakamura S, Kimura F, Sakaguchi T. 1987. Postnatal development of electrical activity in the locus coeruleus. J Neurophysiol 58: 510-524.

Noirot E. 1968. Ultrasounds in young rodents. II. Changes with age in albino rats. Anim Behav 16: 129-134.

Otto T, Poon P. 2006. Dorsal hippocampal contributions to unimodal contextual conditioning. J Neurosci 26: 6603-6609.

Otto T, Cousens G, Herzog C. 2000. Behavioral and neuropsychological foundations of olfactory fear conditioning. Behav Brain Res 110: 119-128.

Overnier JB, Curnow PF. 1969. Classical conditioning, pseudoconditioning, and sensitization in "normal" and forebrainless goldfish. J Comp Physiol Psychol 68: 193-198.

Pattwell SS, Bath KG, Casey BJ, Ninan I, Lee FS. 2011. Selective early-acquired fear memories undergo temporary suppression during adolescence. Proc Natl Acad Sci 108: 1182-1187.

Pattwell SS, Mouly A-M, Sullivan RM, Lee FS. 2013. Developmental components of fear and anxiety in animal models. In Neurobiology of mental illness (ed. Charney DS, Buxbaum JD, Sklar P, Nestler EJ), pp. 593-605, Oxford University Press, New York.

Pavlov IP. 1927. Conditioned reflexes. Oxford University Press, Humphrey Milford, London.

Pedersen PE, Blass EM. 1982. Prenatal and postnatal determinants of the 1st suckling episode in albino rats. Dev Psychobiol 15: 349-355.

Pedersen PE, Williams CL, Blass EM. 1982. Activation and odor conditioning of suckling behavior in 3-day-old albino rats. J Exp Psychol Anim Behav Process 8: 329-341.

Perry BD. 2007. Maltreated children: experience, brain development and the next generation. WW Norton \& Company Incorporated, New York.

Perry R, Sullivan RM. 2014. Neurobiology of attachment to an abusive caregiver: short-term benefits and long-term costs. Dev Psychobiol 56: $1626-1634$

Phelps EA. 2006. Emotion and cognition: insights from studies of the human amygdala. Annu Rev Psychol 57: 27-53.

Phillips AC, Gallagher S, Carroll D. 2009. Social support, social intimacy, and cardiovascular reactions to acute psychological stress. Ann Behav Med 37: 38-45.

Pisano MV, Ferreras S, Krapacher FA, Paglini G, Arias C. 2012. Re-examining the ontogeny of the context preexposure facilitation effect in the rat through multiple dependent variables. Behav Brain Res 233: 176-190.

Pitz GF, Ross RB. 1961. Imprinting as a function of arousal. J Comp Physiol Psychol 54: 602-604.

Pongrácz P, Altbäcker V. 2000. Ontogeny of the responses of European rabbits (Oryctolagus cuniculus) to aerial and ground predators. Can J Zool 78: $655-665$

Poulos AM, Reger M, Mehta N, Zhuravka I, Sterlace SS, Gannam C, Hovda DA, Giza CC, Fanselow MS. 2014. Amnesia for early life stress does not preclude the adult development of posttraumatic stress disorder symptoms in rats. Biol Psychiatry 76: 306-314.

Pugh CR, Tremblay D, Fleshner M, Rudy JW. 1997. A selective role for corticosterone in contextual-fear conditioning. Behav Neurosci 111: 503-511.

Putman BJ, Coss RG, Clark RW. 2015. The ontogeny of antipredator behavior: age differences in California ground squirrels 
(Otospermophilus beecheyi) at multiple stages of rattlesnake encounters. Behav Ecol Sociobiol 69: 1447-1457.

Quirarte GL, Roozendaal B, McGaugh JL. 1997. Glucocorticoid enhancement of memory storage involves noradrenergic activation in the basolateral amygdala. Proc Natl Acad Sci 94: 14048-14053.

Raineki C, Shionoya K, Sander K, Sullivan RM. 2009. Ontogeny of odor-LiCl vs. odor-shock learning: similar behaviors but divergent ages of functional amygdala emergence. Learn Mem 16: 114-121.

Raineki C, Holman PJ, Debiec J, Bugg M, Beasley A, Sullivan RM. 2010a. Functional emergence of the hippocampus in context fear learning in infant rats. Hippocampus 20: 1037-1046.

Raineki C, Moriceau S, Sullivan RM. 2010b. Developing a neurobehavioral animal model of infant attachment to an abusive caregiver. Biol Psychiatry 67: 1137-1145.

Rajecki DW, Lamb ME, Obmascher P. 1978. Toward a general theory of infantile attachment: a comparative review of aspects of the social bond. Behav Brain Sci 1: 417-436.

Rankin CH. 2004. Invertebrate learning: what can't a worm learn? Curr Biol 14: R617-R618.

Revillo DA, Paglini MG, Arias C. 2014. Spontaneous recovery from extinction in the infant rat. Behav Brain Res 274: 149-157.

Richardson R, Paxinos G, Lee J. 2000. The ontogeny of conditioned odor potentiation of startle. Behav Neurosci 114: 1167-1173.

Rincón-Cortés M, Sullivan RM. 2014. Early life trauma and attachment: immediate and enduring effects on neurobehavioral and stress axis development. Front Endocrinol (Lausanne) 5: 33.

Rincón-Cortés M, Barr GA, Mouly AM, Shionoya K, Nuñez BS, Sullivan RM. 2015. Enduring good memories of infant trauma: rescue of adult neurobehavioral deficits via amygdala serotonin and corticosterone interaction. Proc Natl Acad Sci 112: 881-886.

Roozendaal B, Nguyen BT, Power AE, McGaugh JL. 1999. Basolateral amygdala noradrenergic influence enables enhancement of memory consolidation induced by hippocampal glucocorticoid receptor activation. Proc Natl Acad Sci 96: 11642-11647.

Rosenkranz JA, Grace AA. 2002. Dopamine-mediated modulation of odour-evoked amygdala potentials during Pavlovian conditioning. Nature 417: 282-287.

Rosselli-Austin L, Altman J. 1979. The postnatal development of the main olfactory bulb of the rat. J Dev Physiol 1: 295-313.

Roth TL, Sullivan RM. 2001. Endogenous opioids and their role in odor preference acquisition and consolidation following odor-shock conditioning in infant rats. Dev Psychobiol 39: 188-198.

Roth TL, Sullivan RM. 2003. Consolidation and expression of a shock-induced odor preference in rat pups is facilitated by opioids. Physiol Behav 78: 135-142.

Roth TL, Sullivan RM. 2005. Memory of early maltreatment: neonatal behavioral and neural correlates of maternal maltreatment within the context of classical conditioning. Biol Psychiatry 57: 823-831.

Roth TL, Moriceau S, Sullivan RM. 2006. Opioid modulation of Fos protein expression and olfactory circuitry plays a pivotal role in what neonates remember. Learn Mem 13: 590-598.

Roth TL, Raineki C, Salstein L, Perry R, Sullivan-Wilson TA, Sloan A, Lalji B, Hammock E, Wilson DA, Levitt P, et al. 2013. Neurobiology of secure infant attachment and attachment despite adversity: a mouse model. Genes Brain Behav 12: 673-680.

Rudy JW. 1993. Contextual conditioning and auditory cue conditioning dissociate during development. Behav Neurosci 107: 887-891.

Rudy JW. 1994. Ontogeny of context-specific latent inhibition of conditioned fear: implications for configural associations theory and hippocampal formation development. Dev Psychobiol 27: 367-379.

Rudy J, Cheatle M. 1977. Odor-aversion learning in neonatal rats. Science 198: $845-846$.

Rudy JW, Morledge P. 1994. Ontogeny of contextual fear conditioning in rats: implications for consolidation, infantile amnesia, and hippocampal system function. Behav Neurosci 108: 227-234.

Rudy JW, Stadler-Morris S, Albert P. 1987. Ontogeny of spatial navigation behaviors in the rat: dissociation of "proximal"- and "distal"-cue-based behaviors. Behav Neurosci 101: 62-73.

Ryan SJ, Ehrlich DE, Rainnie DG. 2014. Morphology and dendritic maturation of developing principal neurons in the rat basolateral amygdala. Brain Struct Funct 221: 839-854.

Sacco T, Sacchetti B. 2010. Role of secondary sensory cortices in emotional memory storage and retrieval in rats. Science 329: 649-656.

Sanchez MM. 2006. The impact of early adverse care on HPA axis development: nonhuman primate models. Horm Behav 50: 623-631.

Sara SJ, Dyon-Laurent C, Hervé A. 1995. Novelty seeking behavior in the rat is dependent upon the integrity of the noradrenergic system. Cogn Brain Res 2: 181-187.

Schaal B, Marlier L, Soussignan R. 1998. Olfactory function in the human fetus: evidence from selective neonatal responsiveness to the odor of amniotic fluid. Behav Neurosci 112: 1438-1449.
Seay B, Alexander BK, Harlow HF. 1964. Maternal behavior of socially deprived Rhesus monkeys. J Abnorm Psychol 69: 345-354.

Selden NR, Robbins TW, Everitt BJ. 1990. Enhanced behavioral conditioning to context and impaired behavioral and neuroendocrine responses to conditioned stimuli following ceruleocortical noradrenergic lesions: support for an attentional hypothesis of central noradrenergic function. J Neurosci 10: 531-539.

Sevelinges Y, Gervais R, Messaoudi B, Granjon L, Mouly A-M. 2004. Olfactory fear conditioning induces field potential potentiation in rat olfactory cortex and amygdala. Learn Mem 11: 761-769.

Sevelinges Y, Mouly A-M, Raineki C, Moriceau S, Forest C, Sullivan RM. 2011. Adult depression-like behavior, amygdala and olfactory cortex functions are restored by odor previously paired with shock during infant's sensitive period attachment learning. Dev Cogn Neurosci 1: $77-87$.

Shair HN. 2014. Parental potentiation of vocalization as a marker for filial bonds in infant animals. Dev Psychobiol 56: 1689-1697.

Shair HN, Masmela JR, Hofer MA. 1998. The influence of olfaction on potentiation and inhibition of ultrasonic vocalization of rat pups. Physiol Behav 65: 769-772.

Shakhawat AM, Harley CW, Yuan Q. 2012. Olfactory bulb $\alpha 2$-adrenoceptor activation promotes rat pup odor-preference learning via a cAMP-independent mechanism. Learn Mem 19: 499-502.

Shionoya K, Moriceau S, Lunday L, Miner C, Roth TL, Sullivan RM. 2006. Development switch in neural circuitry underlying odor-malaise learning. Learn Mem 13: 801-808.

Shionoya K, Moriceau S, Bradstock P, Sullivan RM. 2007. Maternal attenuation of hypothalamic paraventricular nucleus norepinephrine switches avoidance learning to preference learning in preweanling rat pups. Horm Behav 52: 391-400.

Shionoya K, Hegoburu C, Brown BL, Sullivan RM, Doyère V, Mouly A-M. 2013. It's time to fear! Interval timing in odor fear conditioning in rats. Front Behav Neurosci 7: 128.

Shipley MT, Halloran FJ, de la Torre J. 1985. Surprisingly rich projection from locus coeruleus to the olfactory bulb in the rat. Brain Res 329: 294-299.

Simola N. 2015. Rat ultrasonic vocalizations and behavioral neuropharmacology: from the screening of drugs to the study of disease. Curr Neuropharmacol 13: 164-179.

Siviy SM, Harrison KA, McGregor IS. 2006. Fear, risk assessment, and playfulness in the juvenile rat. Behav Neurosci 120: 49-59.

Small WS. 1899. Notes on the psychic development of the young white rat. Am J Psychol 11: 80-100.

Smith JJ, Shionoya K, Sullivan RM, Wilson DA. 2009. Auditory stimulation dishabituates olfactory responses via noradrenergic cortical modulation. Neural Plast 2009: 1-6.

Smotherman WP. 1982. Odor aversion learning by the rat fetus. Physiol Behav 29: 769-771.

Smotherman WP, Hunt LE, McGinnis LM, Levine S. 1979. Mother-infant separation in group-living rhesus macaques: a hormonal analysis. Dev Psychobiol 12: 211-217.

Sotres-Bayon F, Quirk GJ. 2010. Prefrontal control of fear: more than just extinction. Curr Opin Neurobiol 20: 231-235.

Stanton ME. 2000. Multiple memory systems, development and conditioning. Behav Brain Res 110: 25-37.

Stanton ME, Levine S. 1990. Inhibition of infant glucocorticoid stress response: specific role of maternal cues. Dev Psychobiol 23: 411-426.

Stanton ME, Patterson JM, Levine S. 1985. Social influences on conditioned cortisol secretion in the squirrel monkey. Psychoneuroendocrinology 10: $125-134$.

Stanton ME, Wallstrom J, Levine S. 1987. Maternal contact inhibits pituitary-adrenal stress responses in preweanling rats. Dev Psychobiol 20: $131-145$

Stehouwer DJ, Campbell BA. 1978. Habituation of the forelimb-withdrawal response in neonatal rats. J Exp Psychol Anim Behav Process 4: 104-119.

Stunden CE, Filosa JA, Garcia AJ, Dean JB, Putnam RW. 2001. Development of in vivo ventilatory and single chemosensitive neuron responses to hypercapnia in rats. Respir Physiol 127: 135-155.

Suchecki D, Rosenfeld P, Levine S. 1993. Maternal regulation of the hypothalamic-pituitary-adrenal axis in the infant rat: the roles of feeding and stroking. Dev Brain Res 75: 185-192.

Sullivan RM, Leon M. 1986. Early olfactory learning induces an enhanced olfactory bulb response in young rats. Dev Brain Res 27: 278-282.

Sullivan RM, Wilson DA. 1991. Neural correlates of conditioned odor avoidance in infant rats. Behav Neurosci 105: 307-312.

Sullivan RM, Wilson DA. 1993. Role of the amygdala complex in early olfactory associative learning. Behav Neurosci 107: 254-263.

Sullivan RM, Wilson DA. 1995. Dissociation of behavioral and neural correlates of early associative learning. Dev Psychobiol 28: 213-219.

Sullivan RM, Hofer MA, Brake SC. 1986. Olfactory-guided orientation in neonatal rats is enhanced by a conditioned change in behavioral state. Dev Psychobiol 19: 615-623. 
Sullivan RM, Wilson DA, Leon M. 1989. Norepinephrine and learning-induced plasticity in infant rat olfactory system. J Neurosci 9: 3998-4006.

Sullivan RM, Wilson DA, Wong R, Correa A, Leon M. 1990. Modified behavioral and olfactory bulb responses to maternal odors in preweanling rats. Dev Brain Res 53: 243-247.

Sullivan RM, Taborsky-Barba S, Mendoza R, Itano A, Leon M, Cotman CW, Payne TF, Lott I. 1991. Olfactory classical conditioning in neonates. Pediatrics 87: 511-518.

Sullivan RM, Zyzak DR, Skierkowski P, Wilson DA. 1992. The role of olfactory bulb norepinephrine in early olfactory learning. Dev Brain Res 70: $279-282$.

Sullivan RM, Wilson DA, Lemon C, Gerhardt GA. 1994. Bilateral 6-OHDA lesions of the locus coeruleus impair associative olfactory learning in newborn rats. Brain Res 643: 306-309.

Sullivan RM, Landers M, Yeaman B, Wilson DA. 2000a. Neurophysiology: good memories of bad events in infancy. Nature 407: 38-39.

Sullivan RM, Stackenwalt G, Nasr F, Lemon C, Wilson DA. 2000b. Association of an odor with an activation of olfactory bulb noradrenergic $\beta$-receptors or locus coeruleus stimulation is sufficient to produce learned approach responses to that odor in neonatal rats. Behav Neurosci 114: 957.

Suomi SJ. 1978. Maternal behavior by socially incompetent monkeys: neglect and abuse of offspring. J Pediatr Psychol 3: 28-34.

Takahashi LK. 1992. Developmental expression of defensive responses during exposure to conspecific adults in preweanling rats (Rattus norvegicus). J Comp Psychol 106: 69-77.

Takahashi LK. 1994a. Organizing action of corticosterone on the development of behavioral inhibition in the preweanling rat. Dev Brain Res 81: $121-127$.

Takahashi LK. 1994b. Stimulus control of behavioral inhibition in the preweanling rat. Physiol Behav 55: 717-721.

Takahashi Y, Kiyokawa Y, Kodama Y, Arata S, Takeuchi Y, Mori Y. 2013. Olfactory signals mediate social buffering of conditioned fear responses in male rats. Behav Brain Res 240: 46-51.

Terranova LM, Cirulli F, Laviola G. 1999. Behavioral and hormonal effects of partner familiarity in periadolescent rat pairs upon novelty exposure. Psychoneuroendocrinology 24: 639-656.

Thompson JV, Sullivan RM, Wilson DA. 2008. Developmental emergence of fear learning corresponds with changes in amygdala synaptic plasticity. Brain Res 1200: 58-65.

Tottenham N, Hare TA, Casey BJ. 2011. Behavioral assessment of emotion discrimination, emotion regulation, and cognitive control in childhood, adolescence, and adulthood. Dev Psychol 2: 39.

Upton KJ, Sullivan RM. 2010. Defining age limits of the sensitive period for attachment learning in rat pups. Dev Psychobiol 52: 453-464.

Van Der Poel AM, Miczek KA. 1991. Long ultrasonic calls in male rats following mating, defeat and aversive stimulation: frequency modulation and bout structure. Behaviour 119: 127-142.

Walker DL, Paschall GY, Davis M. 2005. Glutamate receptor antagonist infusions into the basolateral and18 medial amygdala reveal differential contributions to olfactory vs. context fear conditioning and expression. Learn Mem 12: 120-129.
Wallace KJ, Rosen JB. 2001. Neurotoxic lesions of the lateral nucleus of the amygdala decrease conditioned fear but not unconditioned fear of a predator odor: comparison with electrolytic lesions. J Neurosci 21: 3619-3627.

Weldon DA, Travis ML, Kennedy DA. 1991. Posttraining D1 receptor blockade impairs odor conditioning in neonatal rats. Behav Neurosci 105: $450-458$.

Wiedenmayer CP. 2009. Plasticity of defensive behavior and fear in early development. Neurosci Biobehav Rev 33: 432-441.

Wiedenmayer CP, Barr GA. 1998. Ontogeny of defensive behavior and analgesia in rat pups exposed to an adult male rat. Physiol Behav 63: $261-269$.

Wiedenmayer CP, Barr GA. 2001. Developmental changes in responsivity to threat are stimulus-specific in rats. Dev Psychobiol 39: 1-7.

Wiedenmayer CP, Magarinos AM, McEwen BS, Barr GA. 2003. Mother lowers glucocorticoid levels of preweaning rats after acute threat. Ann N Y Acad Sci 1008: 304-307.

Wiedenmayer CP, Magariños AM, McEwen BS, Barr GA. 2005. Age-specific threats induce CRF expression in the paraventricular nucleus of the hypothalamus and hippocampus of young rats. Horm Behav 47: 139-150.

Wilson DA, Leon M. 1988. Spatial patterns of olfactory bulb single-unit responses to learned olfactory cues in young rats. J Neurophysiol 59: $1770-1782$.

Wilson DA, Sullivan RM. 1990. Olfactory associative conditioning in infant rats with brain stimulation as reward. I. Neurobehavioral consequences. Dev Brain Res 53: 215-221.

Wilson DA, Sullivan RM. 1992. Blockade of mitral/tufted cell habituation to odors by association with reward: a preliminary note. Brain Res 594: $143-145$.

Wilson DA, Sullivan RM. 2011. Cortical processing of odor objects. Neuron 72: $506-519$.

Wilson DA, Sullivan RM, Leon M. 1987. Single-unit analysis of postnatal olfactory learning: modified olfactory bulb output response patterns to learned attractive odors. J Neurosci 7: 3154-3162.

Wöhr M, Borta A, Schwarting RKW. 2005. Overt behavior and ultrasonic vocalization in a fear conditioning paradigm: a dose-response study in the rat. Neurobiol Learn Mem 84: 228-240.

Woo CC, Coopersmith R, Leon M. 1987. Localized changes in olfactory bulb morphology associated with early olfactory learning. J Comp Neurol 263: 113-125.

Yuan Q, Harley CW, McLean JH, Knöpfel T. 2002. Optical imaging of odor preference memory in the rat olfactory bulb. J Neurophysiol 87: 3156-3159.

Yuan Q, Harley CW, McLean JH. 2003. Mitral cell $\beta 1$ and 5-HT2A receptor colocalization and cAMP coregulation: a new model of norepinephrine-induced learning in the olfactory bulb. Learn Mem 10: $5-15$.

Received March 16, 2016; accepted in revised form June 2, 2016. 


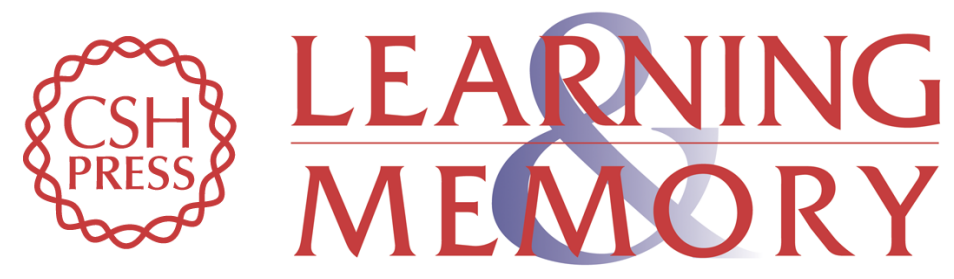

\section{Ecologically relevant neurobehavioral assessment of the development of threat learning}

Julie Boulanger Bertolus, Anne-Marie Mouly and Regina M. Sullivan

Learn. Mem. 2016, 23:

Access the most recent version at doi:10.1101//m.042218.116

References This article cites 239 articles, 39 of which can be accessed free at: http://learnmem.cshlp.org/content/23/10/556.full.html\#ref-list-1

Creative This article is distributed exclusively by Cold Spring Harbor Laboratory Press for the Commons License first 12 months after the full-issue publication date (see

http://learnmem.cshlp.org/site/misc/terms.xhtml). After 12 months, it is available under a Creative Commons License (Attribution-NonCommercial 4.0 International), as described at http://creativecommons.org/licenses/by-nc/4.0/.

Email Alerting Receive free email alerts when new articles cite this article - sign up in the box at the Service top right corner of the article or click here. 